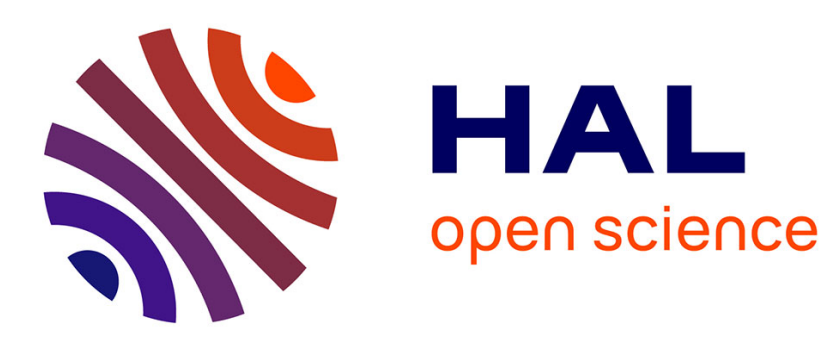

\title{
Growth of interface cracks on consecutive fibers: on the same or on the opposite sides?
}

\author{
Luca Di Stasio, Janis Varna, Zoubir Ayadi
}

\section{To cite this version:}

Luca Di Stasio, Janis Varna, Zoubir Ayadi. Growth of interface cracks on consecutive fibers: on the same or on the opposite sides?. 12th International Conference on Composite Science and Technology, May 2019, Sorrento, Italy. hal-02187507

\section{HAL Id: hal-02187507 https://hal.science/hal-02187507}

Submitted on 17 Jul 2019

HAL is a multi-disciplinary open access archive for the deposit and dissemination of scientific research documents, whether they are published or not. The documents may come from teaching and research institutions in France or abroad, or from public or private research centers.
L'archive ouverte pluridisciplinaire HAL, est destinée au dépôt et à la diffusion de documents scientifiques de niveau recherche, publiés ou non, émanant des établissements d'enseignement et de recherche français ou étrangers, des laboratoires publics ou privés.

\section{(1) (1) $\$$}

Distributed under a Creative Commons Attribution - NonCommercial - NoDerivatives| 4.0 


\title{
GROWTH OF INTERFACE CRACKS ON CONSECUTIVE FIBERS: ON THE SAME OR ON THE OPPOSITE SIDES?
}

\author{
Luca Di Stasio ${ }^{1,2}$, Janis Varna ${ }^{1}$, Zoubir Ayadi ${ }^{2}$, \\ ${ }^{1}$ Luleå University of Technology, University Campus, SE-97187 Luleå, SE \\ ${ }^{2}$ Université de Lorraine, EEIGM, 6 Rue Bastien Lepage, F-54010 Nancy, FR \\ e-mail(s): luca.di.stasio@1tu.se ; janis.varna@1tu.se ; zoubir.ayadi@univ-lorraine.fr
}

Keywords: Polymer Matrix Composite (PMC), Transverse cracking, Debonding, Debond Interaction.

\begin{abstract}
The growth of fiber/matrix interface cracks (debonds) located on consecutive fibers along the through-the-thickness direction is studied in glass fiberepoxy UD composites. Two different families of Representative Volume Elements (RVEs) are developed: the first implements the classic condition of coupling of the vertical displacements to model a unit cell repeating symmetrically along the vertical (through-the-thickness) direction; the second uses a novel set of boundary conditions, proposed here by the authors, to represent a unit cell repeating anti-symmetrically along the vertical direction. The model is analyzed in the context of Linear Elastic Fracture Mechanics (LEFM) and the Mode I and Mode II Energy Release Rate are evaluated to investigate crack growth. The calculation is performed using the Virtual Crack Closure Technique (VCCT) and the evaluation of the J-Integral in the framework of the Finite Element Method (FEM). It is found that Mode I dominated propagation is favored when debonds are located on the same sides of their respective fibers, while larger debond sizes can be achieved in Mode II dominated growth when they lie on the opposite sides. No effect is present when at least two fully bonded fibers are located between the partially debonded ones.
\end{abstract}

\section{INTRODUCTION}

Organized and completed over the last three decades, the three World Wide Failure Exercises (WWFEs) [1-3] represent one of the most comprehensive attempts to date to evaluate the maturity of failure criteria and predictive theories of damage of Fiber-Reinforced Polymer Composites (FRPC). The third and last one (WWFE-III) aims at providing a benchmark for models of sub-critical damage, namely matrix cracking, delamination and fiber failure, by comparing the independent predictions of 12 different approaches (each one from a different individual, group or institution) over 13 test cases [3]. The comparison of predictions by the different theories shows a wide scatter of results, symptomatic of the immaturity of the field [4]. Furthermore, it uncovers the existence of gaps in the knowledge shared by all models. Among these, a clear understanding is still elusive regarding the mechanisms of onset of transverse cracking.

Onset of transverse cracks is determined at the microscopic level by initiation and propagation of fiber-matrix interface cracks $[5,6]$, or debonds. Debonds first grow along the arc direction of the fiber; at a certain critical size they kink out of the interface and lead to the onset of matrix micro-cracks; micro-cracks coalesce together 
forming a through-the-thickness (transverse) crack [7]; the transverse crack finally propagates along the fiber direction, i.e. across the width of the laminate. Thus, understanding the mechanism of debond growth and predicting debond critical arc size (at which kinking starts) represent an important step in the development of precise predictive models of transverse cracking.

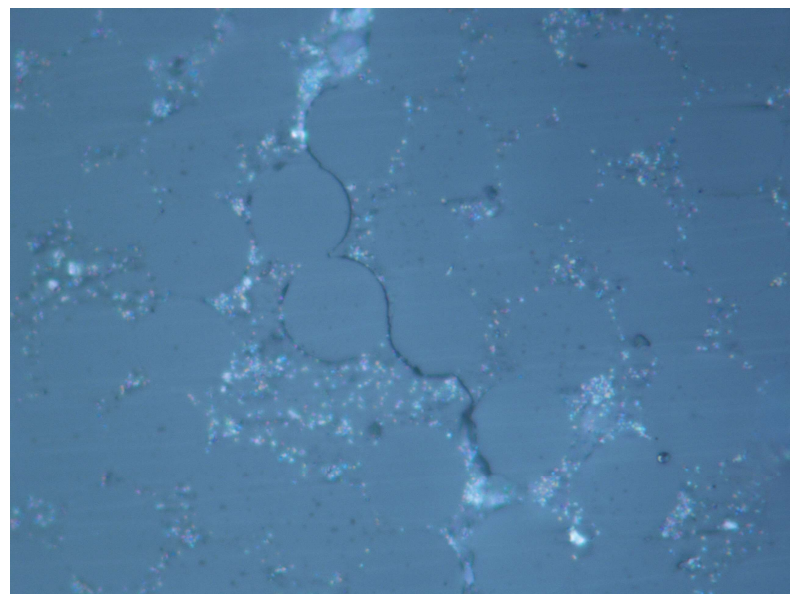

Fig. 1. Debonds in the $90^{\circ}$ layer of a $\left[0^{\circ} / 90^{\circ}\right]_{\mathrm{s}}$ laminate after being subjected to tensile strain in the horizontal direction.

Initial attempts to analyze the mechanics of debonding were based on the linear elastic solution of a single partially debonded fiber in an infinite matrix with an applied tensile stress at infinity, evaluated analytically by using complex potentials [8-10]. It was found that stress and displacement fields have an oscillating singularity at the crack tip, which prevents the use of Stress Intensity Factors (SIFs) as they are not defined in the debond tip's neighborhood. The Energy Release Rate (ERR) is thus, since those first works, used to characterize debond growth. However, the presence of an oscillating singularity does not allow the partition of the ERR into its Mode I and Mode II components at the crack tip. This in turn implies that the Energy Release Rate has to be evaluated over a small but finite distance from the crack tip, which makes the problem suitable for a domain-discretization based solution technique such as the Finite Element Method (FEM) or the Boundary Element Method (BEM). In subsequent works [11,12], it was showed that Toya's analytical solution [10] implies a non-physical interpenetration zone in the crack tip neighborhood. This led to the introduction of a no-interpenetration contact interaction which, solved with the Boundary Element Method (BEM), showed the existence of a contact zone (a finite size region in which crack faces are in contact) for debonds larger than a critical value [12]. In [13], the authors compared the one-debond with respect to the two-symmetric-debonds configuration and found that the former is energetically the most favorable to crack growth. The effect of several load combinations on ERR of a single partially debonded fiber in an effectively infinite matrix was later studied [14-16], as well as the effect of a neighboring fully bonded fiber $[17,18]$. The presence of a second partially debonded fiber, with debonds facing each other, was studied in [19].

Microscopic observations of debond growth, such as the one reported in Fig. 1, show debonds developed on the same as well as the opposite sides of consecutive 
fibers on average aligned along the vertical, i.e. through-the thickness, direction. It is thus interesting to investigate the effect on debond ERR of the position of the next debond on the neighboring partially debonded fiber along the vertical direction. To this end, we develop Representative Volume Elements (RVEs) which, by application of displacement-coupling boundary conditions along the right and left sides, are repeating in a mirror-like fashion horizontally. The use of coupling conditions on the vertical displacement along the upper boundary models the presence of another partially debonded fiber with a debond of equal size and on the same side. In order to model the case of a fiber with a debond of equal size but appearing on the opposite side, we propose a set of anti-symmetric coupling conditions that are applied to the upper boundary. Details regarding coupling conditions, RVEs and Finite Element (FE) discretization are presented in Sec. 2 and Sec. 3, while results are presented and discussed in Sec. 4.

\section{REPRESENTATIVE VOLUME ELEMENTS (RVES)}

Two families of RVE are studied in the present work. RVEs from both families:

1. represent a Uni-Directional (UD) composite, infinite in all 3 directions (length, width and thickness);

2. are solved using plain strain conditions, and thus represent a debond whose length along the fiber is much greater than its arc size;

3. consider two linear, homogeneous, isotropic elastic phases, i.e. glass fiber and epoxy matrix, whose properties are reported in Table 1;

4. possess a centrally-placed partially debonded fiber and have a total of $n$ fibers along the horizontal direction (loading direction, transverse to composite $0^{\circ}$ direction) and $k$ in the vertical (i.e. through-the-thickness) direction;

5. repeat infinitely along the horizontal direction in a mirror-like way (the next repeated element to the right is the mirror image with respect to the right-side boundary) thanks to the application of coupling conditions on the horizontal displacement along the right and left sides of the element;

6. are symmetric with respect to the horizontal axis, which allows the discretization of only half RVE through the application of symmetry boundary conditions on the lower side;

7. are subject to tensile loading in the form of applied displacement corresponding to a $x$-strain level of $1 \%$.

The distinction between the two families of RVE lies in the boundary conditions applied along the upper side.

\begin{tabular}{ccc}
\hline Material & E [GPa] & $\mathbf{v}[-]$ \\
\hline glass fiber & 70.0 & 0.2 \\
epoxy & 3.5 & 0.4 \\
\hline
\end{tabular}

Table 1. Material properties of glass fiber and epoxy adopted in the present study.

The first family has coupling conditions applied to the vertical displacement of the points belonging to the upper side, such that

$$
u_{y}(x, h)=u_{y}^{v}
$$


where $h$ is the height of the RVE and $u_{y}^{v}$ is the unknown vertical displacement of the upper boundary due to Poisson's effect, which is evaluated as part of the elastic solution.

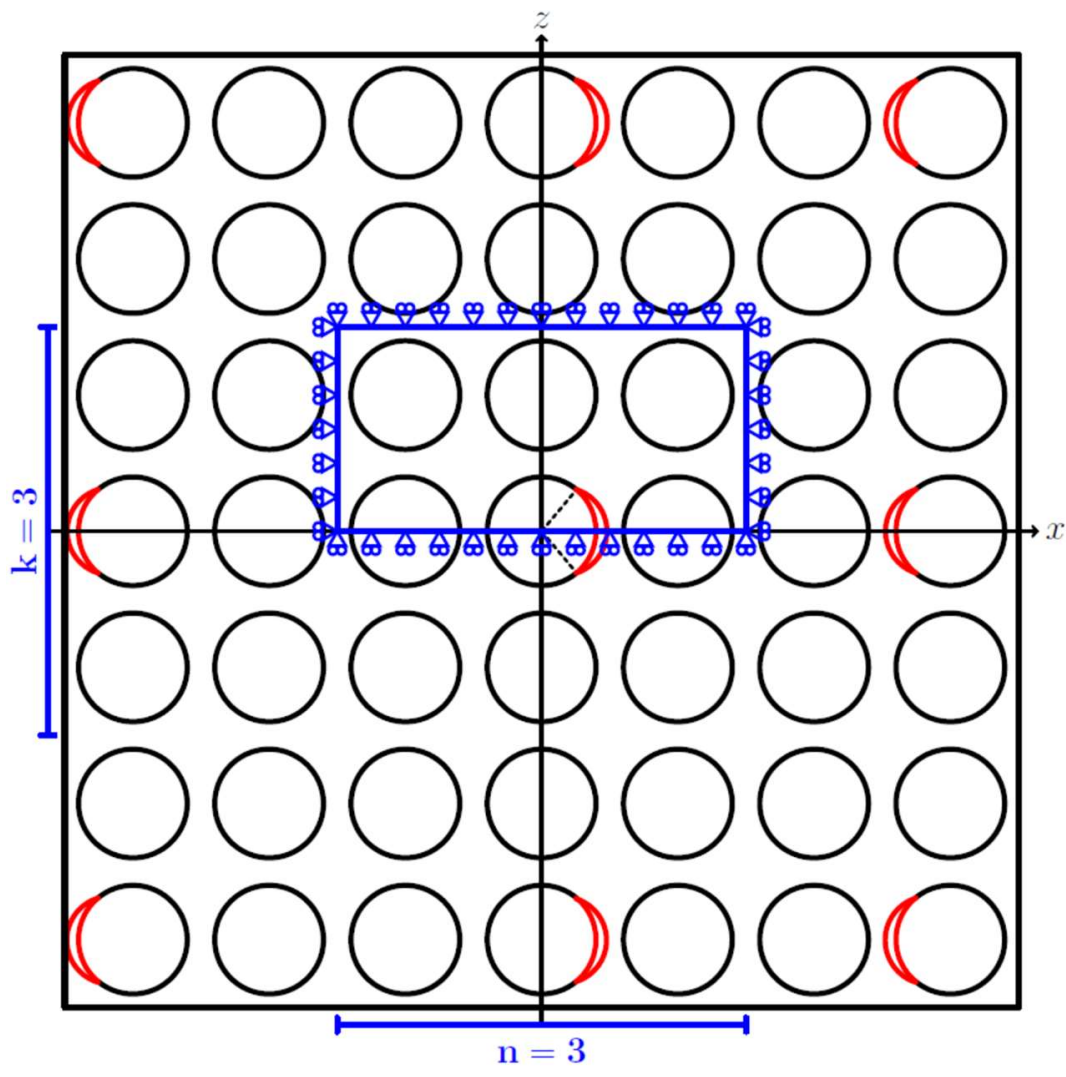

Fig. 2. Representative Volume Element $n x k$ - coupling of a UD composite with debonds appearing every $n-1$ and every $k-1$ undamaged fibers respectively in the horizontal and vertical direction. In the vertical direction, on fibers belonging to the same "column", debonds are located always on the same side.

This condition implies that the element is repeating along the vertical direction, symmetrically with respect to the upper boundary line. It means, in turn, that the next debonded fiber will have a debond on the same side as the preceding one (see Fig. 2). We will refer to this set of RVEs as $n \times k-$ coupling, where $n$ and $k$ are the number of fibers respectively in the RVE's horizontal and vertical direction.

The second type of RVE has a set of boundary conditions applied to the upper side of the form:

$$
\begin{aligned}
u_{y}(x, h)-u_{y}(0, h) & =-\left(u_{y}(-x, h)-u_{y}(0, h)\right), \\
u_{x}(x, h) & =-u_{x}(-x, h),
\end{aligned}
$$

where $h$ is the height of the RVE and $u_{y}(0, h)$ is the unknown vertical displacement of the upper boundary's mid-point due to Poisson's effect, which is evaluated as part of the elastic solution. This condition, an anti-symmetric coupling condition, implies that the element is repeating along the vertical direction, antisymmetrically with respect to the upper boundary line, i.e. the next debonded fiber will have a debond on the opposite side with respect to the preceding one (see Fig. 3). 


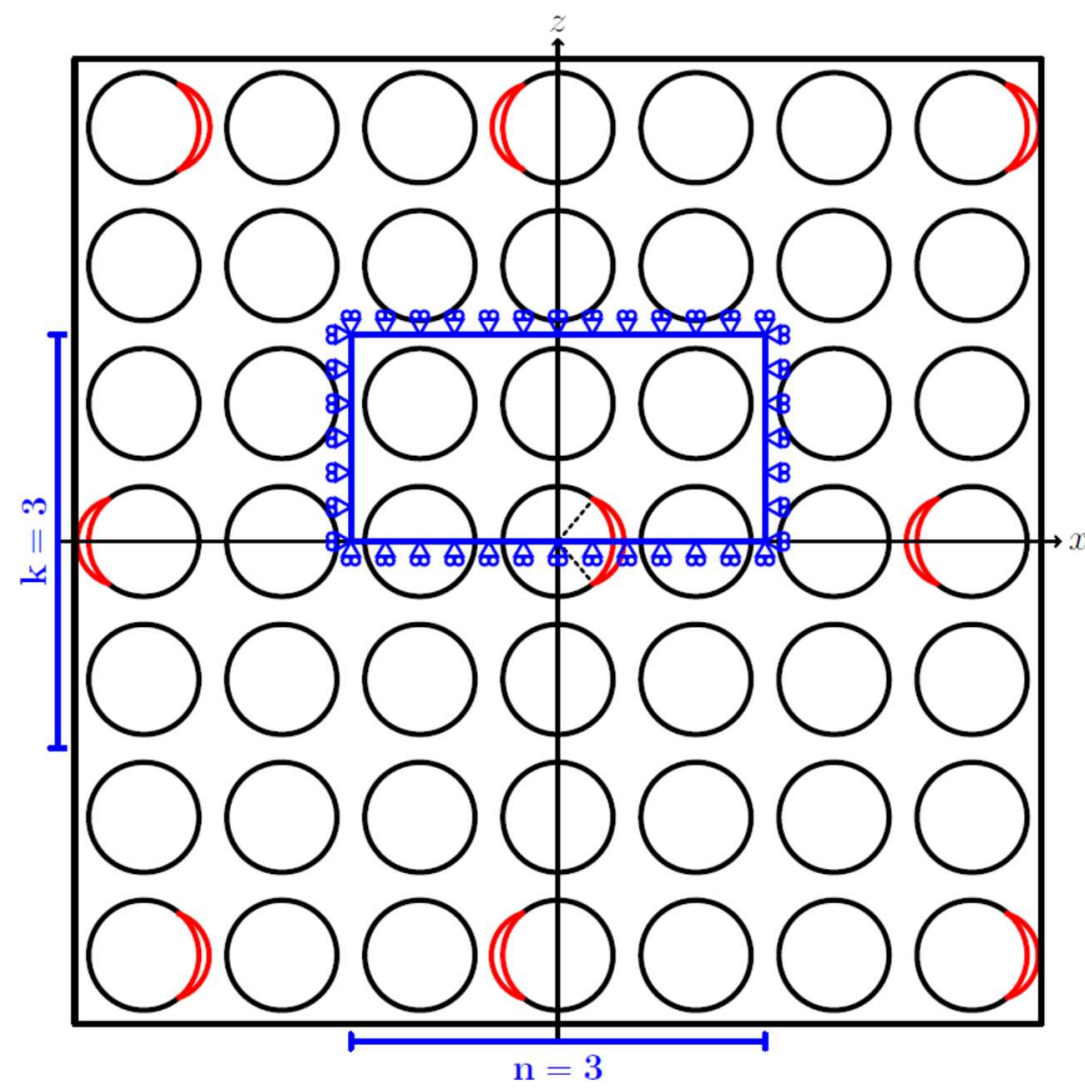

Fig. 3. Representative Volume Element $n \times k-$ asymm of a UD composite with debonds appearing every $n-1$ and every $k-1$ undamaged fibers respectively in the horizontal and vertical direction. In the vertical direction, on fibers belonging to the same "column", debonds are located on the opposite sides of consecutive fibers.

To the authors' knowledge, this is the first time that this kind of coupling condition is proposed to model the growth of multiple debonds on alternating sides of consecutive fibers along the through-the-thickness direction. We will refer to this set of RVEs as $n x k-$ asymm, where $n$ and $k$ are the number of fibers respectively in the RVE's horizontal and vertical direction.

\section{FINITE ELEMENT SOLUTION}

The length and height of the generic $n x k$-coupling and $n \times k-$ asymm RVE are respectively defined as

$$
l=n \cdot 2 L \quad h=\frac{k \cdot 2 L}{2},
$$

where $2 L \cdot 2 L$ is the size of a 1 -fiber unit cell (see Fig. 4) and $L$ is determined by

$$
L=\frac{R_{f}}{2} \sqrt{\frac{\pi}{V_{f}}},
$$

where $R_{f}$ and $V_{f}$ are respectively the fiber radius and volume fraction. The fiber radius is assumed to be always equal to $1 \mu \mathrm{m}$ : within the scope of Linear Elastic Fracture Mechanics (LEFM), the ERR is linearly proportional to the fiber radius, which is representative of the crack size. Thus, the fiber radius represents a scale parameter and a simple multiplication is needed to obtain the ERR for a different 
value of the fiber radius. The volume fraction is assumed to be homogeneous and equal to $60 \%$.

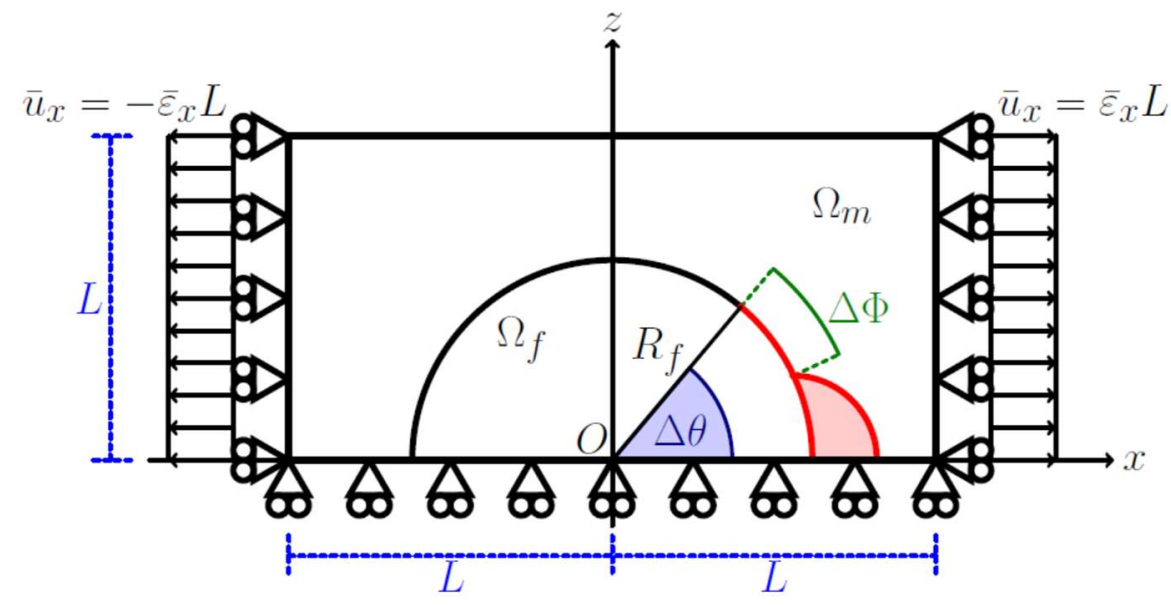

Fig. 4. Schematic of the model with its main parameters.

The debond size is equal to $2 \Delta \theta$, while the contact zone size is denoted by $\Delta \Phi$. The crack faces interaction in the contact zone is assumed to be frictionless. Consequently, crack faces are modeled as surfaces whose interaction is defined by conditions of no-interpenetration and frictionless sliding.

The model is discretized and solved using the Finite Element Method (FEM) in the Abaqus environment [20]. The Mode I and Mode II ERR are computed using the Virtual Crack Closure Technique [21] implemented in a custom Python routine, while the total ERR is evaluated by means of the Abaqus built-in J-Integral method [22]. The mesh is composed by 8-nodes quadrilaterals and 6-nodes triangles with quadratic shape functions. In order to ensure the convergence of the Energy Release Rate, a regular mesh of quadrilaterals with almost unitary aspect ratio is used in the crack tip neighborhood. The size of the elements in this region is characterized by their angular size $\delta$, which is always equal to $0.05^{\circ}$ in our analysis. The convergence of the model has been verified on the 1-fiber RVE with an infinite matrix $\left(V_{f} \rightarrow 0\right)$ with respect to the BEM results presented in [17]. By comparing FEM and BEM results, it is possible to estimate the relative accuracy of our results at around 5\%. It implies that differences in the ERR smaller than this value cannot be considered significant.

\section{RESULTS \& DISCUSSION}

We first devote our attention to the $n \times 1-$ coupling and $n \times 1-$ asymm Representative Volume Elements. They both represent an infinite UD in which a column (i.e. a vertical line) made of only partially debonded fibers, with debonds of equal size, is repeating along the horizontal (loading, transverse to laminate $0^{\circ}$ ) direction every $n-1$ columns of fully bonded fibers.

In the $n \times 1$-coupling RVE, debonds appear always on the same side of consecutive fibers belonging to the same column, i.e. the debond mid-point is always at $0^{\circ}$ or $180^{\circ}$ inside the same column of partially debonded fibers (see Figure 2). In the $n \times 1$-asymm RVE instead, debonds are placed on alternating sides of consecutive fibers belonging to the same column of damaged fibers, i.e. the debond mid-point is located alternatively at $0^{\circ}$ and $180^{\circ}$ inside the same column (see Figure 
3). Observing Fig. 5 and Fig. 6, it is possible to notice that, for both types of RVE, Mode I and Mode II ERR increase when the spacing between columns of damaged fibers (measured in terms of number of columns of fully bonded fibers) increases.

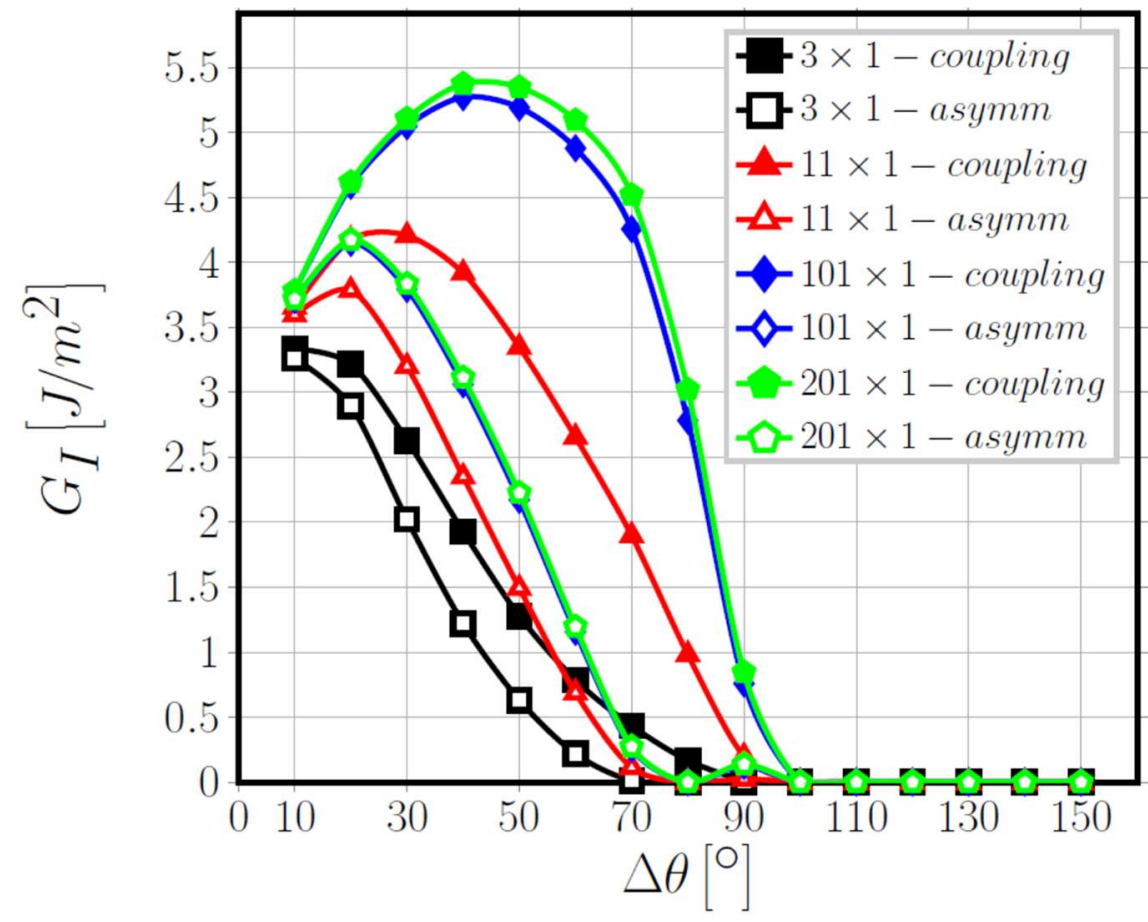

Fig. 5. Comparison of Mode I ERR between $n \times 1-$ coupling and $n \times 1-$ asymm RVEs, $V_{f}=$ $60 \%, \varepsilon_{x}=1 \%$.

This is due to the $x$-strain magnification effect: the presence of an increasing number of fully bonded fibers between consecutive debonds in the horizontal direction causes, for the same applied macroscopic strain, an increase of the local $x$ strain in the debond tip neighborhood. Given that the ERR is equal to the integral of the product of stresses and displacements at the debond tip, a magnification of the strain, and thus of the displacement, leads to an increase in the value of ERR.

In reverse, this effect can be interpreted as a consequence of crack shielding: increasing the number of columns of partially debonded fibers in the UD decreases the local magnitude of the strain at the debond tip, as the presence of a debond causes a gap in the displacement field. In turn, decreasing the magnitude of the displacements in the debond neighborhood decreases the ERR.

As for smaller debonds the x-displacement contributes mainly to the Crack Opening Displacement (COD), the magnitude increase of the local $x$-displacement causes a delay in the contact zone onset (corresponding to $G_{I}=0$ ) by $\sim 10^{\circ}$ in both sets of RVEs: from $70^{\circ}$ to $80^{\circ}$ for $n \times 1-$ asymm, from $90^{\circ}$ to $100^{\circ}$ for $n \times 1-$ coupling (see Fig. 5). On the other hand, for larger debonds the x-displacement contributes mainly to the Crack Sliding Displacement (CSD) and its increase causes the maximum of $G_{I I}$ to occur at larger debond sizes: from $80^{\circ}$ to $100^{\circ}$ for $n \times 1-$ asymm, from $60^{\circ}$ to $90^{\circ}$ for $n \times 1-$ coupling (see Fig. 6).

Comparing the two families of RVE, it is possible to see in Fig. 5 that $G_{I}$ is consistently higher for $n \times 1-$ coupling. Similarly, the onset of the contact zone in 
$n \times 1$-coupling (at $90^{\circ}-100^{\circ}$ ) is significantly delayed with respect to $n \times 1-\operatorname{asymm}\left(\right.$ at $\left.70^{\circ}-80^{\circ}\right)$.

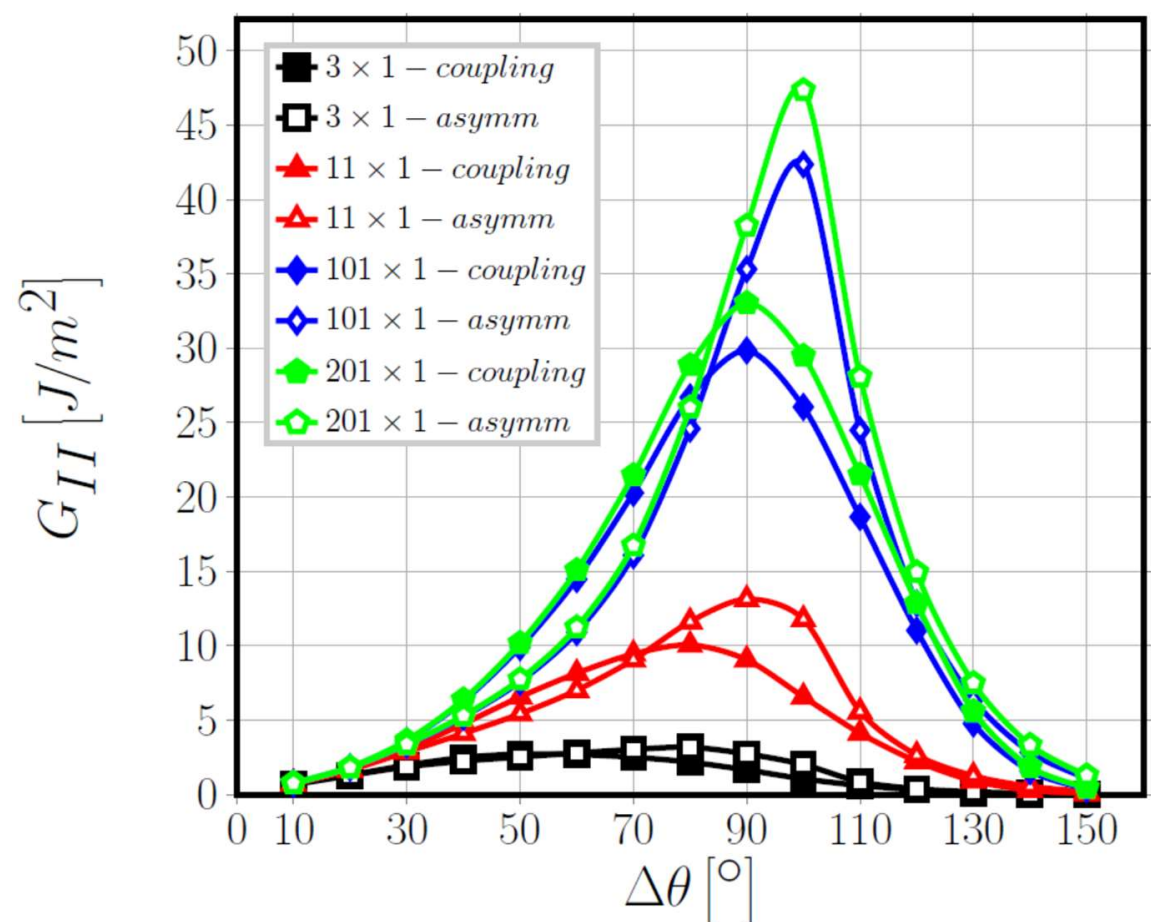

Fig. 6. Comparison of Mode II ERR between $n \times 1-$ coupling and $n \times 1-$ asymm RVEs, $V_{f}=$ $60 \%, \varepsilon_{x}=1 \%$.

In the $n x 1-$ coupling RVE, in the case of smaller Mode I dominated debonds, the presence of a debond on the same side of the consecutive fiber provides a local free surface which causes the matrix to shrink away from the surface of the two fibers. This mechanism favors the opening of crack faces, and thus an increase in Mode I ERR. In $n \times 1-$ asymm RVE, on the other hand, the matrix in the debond tip neighborhood is constrained by the next fiber (debonded on the opposite side) which reduces the $\mathrm{x}$-displacement.

Comparing Mode II ERR for the two types of RVE in Fig. 6, $G_{I I}$ appears to be higher for $n \times 1-$ asymm RVEs than for $n \times 1-$ coupling in the $80^{\circ}-100^{\circ}$ range while slightly lower for smaller debonds $\left(<80^{\circ}\right)$. Mode II peak value is delayed in $n \times 1-$ asymm to larger debond sizes $\left(80^{\circ}-100^{\circ}\right)$ than in $n \times 1$-coupling $\left(60^{\circ}-90^{\circ}\right)$. For larger values of $\Delta \theta\left(\sim 80^{\circ}-100^{\circ}\right)$, the presence of a local free surface due to a debond on the same side of the consecutive fiber causes a decrease in the x-displacement at the crack tip, which now contributes mainly to Mode II. When debonds are located on opposite sides of consecutive fibers, the presence of a fully bonded interface leads instead to a magnification of the x-displacement at the crack tip, and thus an increase in $G_{I I}$. When debonds on consecutive fibers reach a size of $\sim 110^{\circ}$, they are creating two free surfaces close to each other, which cause a relaxation in the elastic fields in both types of RVE. This leads to a quick decrease in the value of Mode II ERR and makes the results of the two different RVEs practically indistinguishable. 


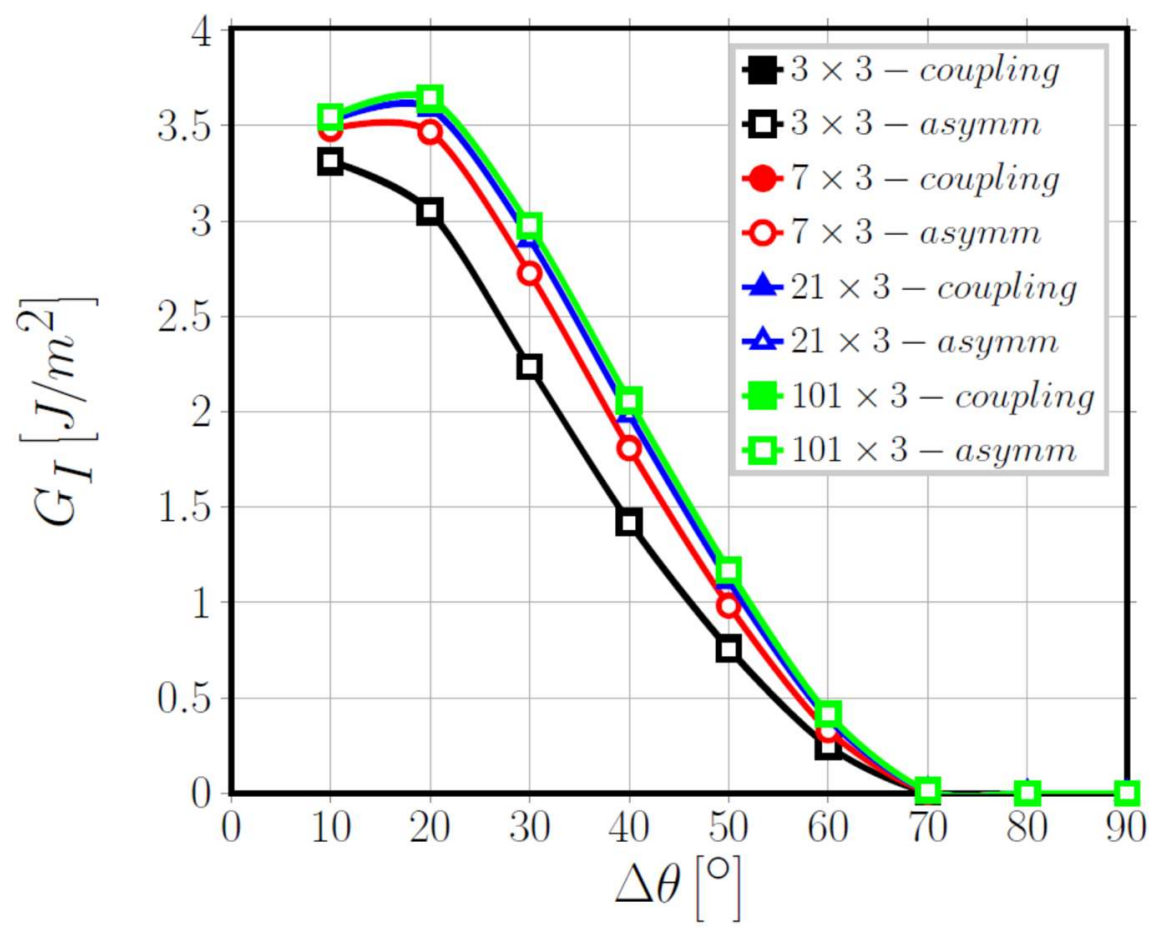

Fig. 7. Comparison of Mode I ERR between $n \times 3-$ coupling and $n \times 3-$ asymm RVEs, $V_{f}=$ $60 \%, \varepsilon_{x}=1 \%$.

It is at this point interesting to investigate the effect of the presence of fully bonded fibers between two consecutive partially debonded fibers in the through-the-thickness direction.

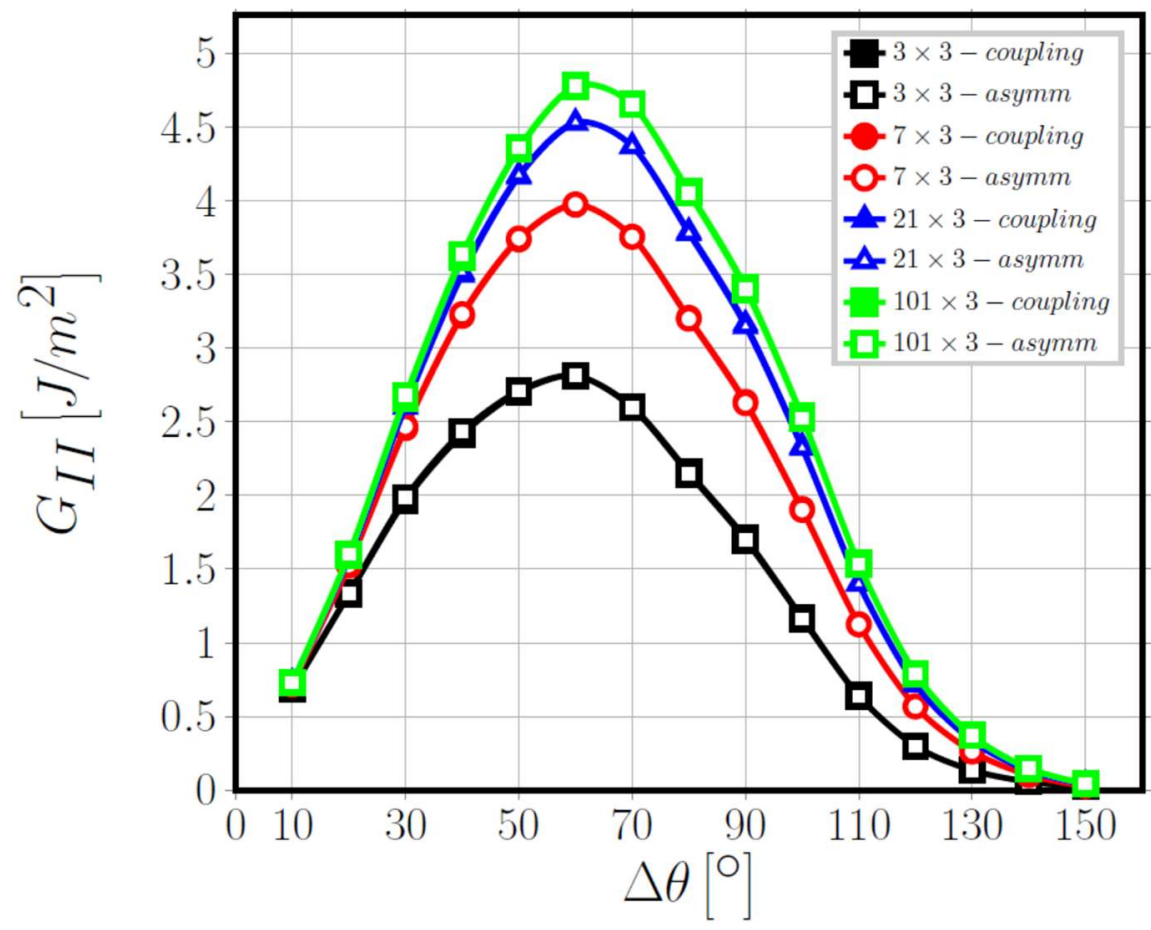

Fig. 8. Comparison of Mode II ERR between $n \times 3-$ coupling and $n \times 3-$ asymm RVEs, $V_{f}=$ $60 \%, \varepsilon_{x}=1 \%$. 
A comparison of Mode I and of Mode II ERR between $n \times 3$-coupling and $n \times 3-$ asymm are reported respectively in Fig. 7 and in Fig. 8: the presence of only one fully bonded fiber on top and below the partially debonded one in the RVE (two fully bonded fibers between two consecutive debonded ones in the UD) already makes the results of the two different RVEs practically identical. The effect of the relative position (same or opposite sides of the fibers) of two consecutive debonds in the through-the-thickness direction is thus an extremely localized problem: the presence of just two fully bonded fibers in between makes the two configurations indistinguishable, at least from an energy point of view.

\section{CONCLUSIONS}

Two different types of Representative Volume Element have been developed to study the effect of the relative position (same or opposite sides of the fibers) of consecutive debonds in the through-the thickness direction. The RVEs are repeating in the horizontal direction thanks to the application of coupling conditions on the horizontal displacements on their right and left sides. The case with debonds located on the same side of their respective fibers is modeled using conditions of coupling of the vertical displacements on the top boundary, which corresponds to the element repeating in the vertical (through-the-thickness) direction in a symmetric way. In order to model the second configuration, with debonds placed on opposite sides of consecutive fibers, a novel set of coupling conditions is introduced, which models an element repeating in the vertical direction anti-symmetrically.

Debond growth is characterized through the evaluation of Mode I and Mode II Energy Release Rate by means of the Virtual Crack Closure Technique. The comparison between the ERR of the two families of RVE provides insights into the effect of the relative position of debonds (same or opposite sides of the respective fiber) belonging to fibers aligned in the vertical or through-the-thickness direction, i.e. located in the same "column" of fibers. It has been found that:

1. the relative position of debonds, i.e. same or opposite sides of vertically aligned fibers, influences the ERR only if debonds are located on consecutive fibers: the presence of just one fully bonded fiber on top and below the debonded one in the RVE (two fully bonded between two consecutive debonded fibers in the UD) makes the ERR unaffected by debonds' relative position;

2. when debonds are located on consecutive vertically-aligned fibers, $G_{I}$ is higher and contact zone onset is delayed if debonds are on the same side of their respective fibers;

3. no significant difference in $G_{I I}$ between the two RVE families can be observed except in the range $\Delta \theta=80^{\circ}-100^{\circ}$, in which it is higher when debonds are located on opposite sides of consecutive vertically-aligned fibers.

Given that debond growth is likelier when the Mode Ratio is Mode I dominated, it is reasonable to expect that the growth of consecutive vertically-aligned debonds with no fully bonded fiber in between is favored when they are located on the same side of their respective fibers. However, assuming that the applied strain is high enough to cause debond growth, larger debond sizes are reached when debonds are on opposite sides. When instead vertically-aligned debonds are separated by fully bonded fibers, 
neither configuration (debonds on the same or opposite sides of the debonded fibers) is favored from an Energy Release Rate point of view.

\section{ACKNOWLEDGEMENTS}

Luca Di Stasio gratefully acknowledges the support of the European School of Materials (EUSMAT) through the DocMASE Doctoral Program and the European Commission through the Erasmus Mundus Program.

\section{REFERENCES}

[1] Hinton, M. J., Kaddour, A.S., Soden P.D., 2004. Chapter 1.1 - The world-wide failure exercise: Its origin, concept and content. Editor(s): M.J. Hinton, A.S. Kaddour, P.D. Soden, Failure Criteria in Fibre-Reinforced-Polymer Composites, Elsevier, 2-28.

[2] Hinton, M., Kaddour, A., 2012. The background to the Second World-Wide Failure Exercise. Journal of Composite Materials, 46 (19-20), pp. 2283-2294.

[3] Kaddour, A., Hinton, M., Smith, P., Li, S., 2013. The background to the third world-wide failure exercise. Journal of Composite Materials, 47 (20-21), pp. 2417-2426.

[4] Kaddour, A., Hinton, M., Smith, P., Li, S., 2013. A comparison between the predictive capability of matrix cracking, damage and failure criteria for fibre reinforced composite laminates: Part A of the third world-wide failure exercise. Journal of Composite Materials, 47 (20-21), pp. 2749-2779.

[5] Bailey, J. E., Parvizi, A., 1981. On fibre debonding effects and the mechanism of transverse-ply failure in cross-ply laminates of glass fibre/thermoset composites. Journal of Materials Science 16 (3), pp. 649-659.

[6] J. E. Bailey, P. T. Curtis, A. Parvizi, 1979. On the transverse cracking and longitudinal splitting behaviour of glass and carbon fibre reinforced epoxy cross ply laminates and the effect of Poisson and thermally generated strain, Proceedings of the royal society A: Mathematical, physical and Engineering sciences, 366 (1727), pp. 599-623.

[7] Zhang, H., Ericson, M. L., Varna, J., Berglund, L.A., 1997. Transverse singlefibre test for interfacial debonding in composites: 1. Experimental observations. Composites Part A: Applied Science and Manufacturing, 28 (4), pp. 309-315.

[8] England, A. H., 1996. An arc crack around a circular elastic inclusion, Journal of Applied Mechanics, 33 (3) pp. 637.

[9] Perlman, A., Sih, G., 1967. Elastostatic problems of curvilinear cracks in bonded dissimilar materials. International Journal of Engineering Science, 5 (11), pp. 845-867.

[10] Toya, M., 1974. A crack along the interface of a circular inclusion embedded in an infinite solid. Journal of the Mechanics and Physics of Solids, 22 (5).

[11]Paris, F., Cano, J. C., Varna, J., 1996. The fiber-matrix interface crack: a numerical analysis using boundary elements. International Journal of Fracture, 82 (1), pp. 11-29.

[12] Varna, J., Paris, F., Cano, J. C., 1997. The effect of crack-face contact on fiber/matrix debonding in transverse tensile loading. Composites Science and Technology 57 (5), pp. 523-532.

[13] Garcia, I., Mantic, V., Graciani, E., 2015. Debonding at the fibre-matrix interface 
under remote transverse tension. one debond or two symmetric debonds? European Journal of Mechanics - A/Solids 53, pp. 75-88.

[14]Correa, E., Gamstedt, E., Paris, F., Mantic, V., 2007. Effects of the presence of compression in transverse cyclic loading on fibre-matrix debonding in unidirectional composite plies. Composites Part A: Applied Science and manufacturing, 38 (11).

[15]Correa, E., Paris, F., Mantic, V., 2013. Effect of the presence of a secondary transverse load on the inter-fibre failure under tension. Engineering Fracture Mechanics, 103, pp. 174-189.

[16]Correa, E., Paris, F., Mantic, V., 2014. Effect of a secondary transverse load on the inter-fibre failure under compression. Composites Part B: Engineering 65, 5768.

[17] Sandino, C., Correa, E., Paris, F., 2016. Numerical analysis of the influence of a nearby fibre on the interface crack growth in composites under transverse tensile load. Engineering Fracture Mechanics 168, pp. 58-75.

[18]Zhuang, L., Pupurs, A., Varna, J., Talreja, R., Ayadi, Z., 2018. Effects of interfiber spacing on fiber-matrix debond crack growth in unidirectional composites under transverse loading. Composites Part A: Applied Science and Manufacturing, 109, pp. 463-471.

[19] Varna, J., Zhuang, L. Q., Pupurs, A., Ayadi, Z., 2017. Growth and interaction of debonds in local clusters of fibers in unidirectional composites during transverse loading. Key Engineering Materials, 754, pp. 63-66.

[20] Simulia, Providence, RI, USA, 2012. ABAQUS/Standard User's Manual, Version 6.12.

[21]Krueger, R., 2004. Virtual crack closure technique: History, approach, and applications. Applied Mechanics Reviews, 57 (2), pp. 109.

[22]Rice, J. R., 1968. A path independent integral and the approximate analysis of strain concentration by notches and cracks. Journal of Applied Mechanics, 35 (2), pp. 379. 
Please sign and date this form and retain a copy for your records. Please include this page with your paper/abstract.

\section{TERMS AND CONDITIONS}

By submitting an abstract/full paper all authors agree to the below terms and conditions.

- Submitting authors must declare that the abstract/s submitted are the original work of at least one author/presenter.

- If the abstract/full paper is accepted as an oral and/or poster, at least one abstract author will register, pay and attend ICCST/12.

- Presenting authors are required to register and pay for the conference. No funding is provided to presenters.

- If the abstract/full paper is selected, consent is provided for the presentation slides (for oral presenters), video, audio recording and photos taken during the oral presentation/poster presentation to be used and published by ICCST/12 including being provided to delegates of ICCST/12.

- Submitting authors must declare the work described in the abstract/full paper has appropriate approval under local, ethical and animal experimentation rules.

- Submitting authors must declare that their work does not conflict with any existing copyright agreements with alternate publishers.

\section{COPYRIGHT RELEASE AGREEMENT}

By Submitting an abstract/full paper, the Owner/s:

- warrants that he/she is the sole creator and/or owner of all copyrights in the manuscript, and that he/she has full power to enter into this Agreement and that this Agreement does not infringe the rights of any third party.

- The Owner/s does hereby assign and transfer to ICCST/12 the following copyrights in the manuscript, without reservation or exclusion.

- The Owner agrees that the Assignee shall from here on own the said copyrights in the manuscript, to benefit and dispose of these rights in any way and at his/her sole discretion.

- The Parties agree that this Agreement shall be binding upon the legal successors and assigns.

\begin{tabular}{|l|l|l|}
\hline Paper Title: & $\begin{array}{l}\text { Growth of interface cracks on consecutive fibers: on the } \\
\text { same or on the opposite sides? }\end{array}$ \\
\hline $\begin{array}{l}\text { Date: } \\
19 / 04 / 2019\end{array}$ & $\begin{array}{l}\text { Lead Author: } \\
\text { Luca Di Stasio }\end{array}$ \\
\hline
\end{tabular}

